\title{
OPTIMIZATION OF DESIGN AND PERFORMANCE CHARACTERISTICS OF HEATING SYSTEM OF PRESS EQUIPMENT
}

\author{
${ }^{1}$ Andrey Vladimirovich Ostroukh, ${ }^{2}$ Alexey Olegovic Glebov, \\ ${ }^{2}$ Sergey Vladimirovich Karpov, ${ }^{2}$ Sergey Viktorovich Karpushkin and \\ ${ }^{2}$ Mikhail Nikolaevich Krasnyanskiy \\ ${ }^{1}$ Department of Automated Control Systems, \\ Moscow Automobile and Road Construction State Technical University, Moscow, Russia \\ ${ }^{2}$ Department of Automated Design of Technological Equipment, \\ Tambov State Technical University, Tambov, Russia
}

Received 2014-02-17; Revised 2014-02-21; Accepted 2014-04-04

\begin{abstract}
The manufacturing of rubber products has a steady growth. Thereby modernization of existing and design of new advanced equipment for this industry is a topical problem. The article is devoted to optimization of design and performance characteristics of press equipment's heating system, realizing the process of hot vulcanization rubber in molds. The optimization methodic is based on minimization of temperature difference on the platen's working surface and can be applied to platens with any type of heating. The choice and justification of methods for formation, verification and finding an extremum of optimality criterion's response surface has implemented. The example of developed methodic application for optimization a heating platen with rectangular inductors has shown which was made possible to reduce the temperature difference in 2 times. According to results of research the choice of preferable experimental designs for that type of problems has found.
\end{abstract}

Keywords: Press Equipment, Heating Platen, Optimization, Design of Experiments

\section{INTRODUCTION}

Press equipment is widespread in industry. The most often it is used for hot vulcanization of rubber products in metal press molds, in manufacturing of a different construction materials in a shape of a plate as well as curing metal products. Increasingly strict requirements are demanded to that equipment which is primarily related with an accuracy of temperature heating. The analysis of publications (Ilona et al., 2008; Karpov and Karpushkin, 2012) has shown that admissible heating unevenness (maximum temperature difference on the surface of a heating platen by the specified heating time) was $\pm 10^{\circ} \mathrm{C}$, later it was $\pm 5^{\circ} \mathrm{C}$. Nowadays it is not rare to meet in terms of reference for the development of the press the unevenness of $\pm 1^{\circ} \mathrm{C}$.

Corresponding Author: Andrey Vladimirovich Ostroukh, Department of Automated Control Systems, Moscow Automobile and Road construction State Technical University, Moscow, Russia

In some cases the design of equipment with such high degree of heating uniformity is complicated by increased parameters of technological process: Pressing forces 4-5 $\mathrm{MN}$ and operating temperatures $400-500^{\circ} \mathrm{C}$. It is real industrial task for example in the case of thermal straightening of responsible metal parts on the press which is heated for the following exposure with stress and temperature changes over time. To meet these requirements it is necessary to conduct complex optimization of structure and mode characteristics of press equipment. However, there are no methods in the literature that allow designing electro thermal installations with a given degree of non-uniformity temperature field for specific technological processes realization. Creation of such methodic is impossible 39

AJAS 
without comprehensive theoretical and experimental analysis of press equipment heating systems (Dmitrievskii et al., 2012).

In general the statement of a problem of heating system for press equipment optimization can be formulated as follows: It is necessary to find such structure (number and mutual arrangement of heaters, length, width and position of the each heater center) and mode (power of heater) characteristics of press' platens, which will form required temperature field in the volume of compressible products. Thus problem can be solved in two ways.

The first way is based on the modeling of temperature fields in the products (Abhilash et al., 2010) for minimization of temperature difference in their volume. That approach is associated with some difficulties. Firstly, the products are often has an intricate geometry and significant computing sources are necessary to taking it into account. Secondly, the reliable data of thermo-physical properties of materials is required for modeling temperature fields in the volume of products. Their obtaining is related to the solution of inverse heat conduction, diffusion and kinetics problems with implementation of experimental information about changing of temperature fields during the specially organized experiment (Dmitriev et al., 2010). Moreover, it is necessary to consider thermal effects that are enhanced with increasing of mass of products (Avaev et al., 2010). That's why the use of the first method is not always feasible.

The second way is based on the modeling of heating of press' platens for minimizing the difference of temperature on the working surface (Karpushkin et al., 2011). This approach is based on the assertion that a uniform temperature field will provide uniform heating of products and press molds parts. Note that in some way this method is a "compromise", because signify simplification of the original problem: The geometry model has only heating platen which can be represented as a set of bodies of canonical form.

The results of the optimization solutions obtained with the first method are applicable only to the specific products. However, according to the practice, heating platens are built for manufacturing a wide range of sizes and nomenclature i.e., should be universal. For this reason it was decided to create methodic of optimization on the base of modeling a heating of a press' platens.

According to the existing publications genetic algorithms are popular for solving tasks of miscellaneous electro thermal systems optimization.
For example, it is used for optimization of heating of metal disks (Galunin et al., 2001) and cylindrical pieces (Mihaela et al., 2009), for modeling of controlling of power transmission with implementation of unified power flow controller (Taher et al., 2008). However, the following factors are substantially complicates the optimization procedure based on genetic algorithms:

- The complexity of the physical processes during the heating of press' platens as well as a lot of influencing factors (Maruthachalam and Palaniswamy, 2011)

- An important for practice heating processes are non-stationary

- The solving of mathematical model's equations, required for determining temperature fields (Malygin et al., 2013), associated with significant calculation time. That's why the use of optimization techniques that performs a multiple solving of equations of mathematical model is difficult because of lack calculation sources and enormous calculation times. This circumstance is amplified by a lot of objective parameters of platens

- Numerical calculations showed different impact of structure and mode characteristics on the temperature field of platens which is differ by the number and relative position of heaters. Therefore it is impossible to develop universal recommendations for optimal design and assessment of heating platens

Primarily these factors lead to obtaining of local extremum or even controversial points near the initial values.

This study is dedicated to the development of optimization methodic for structural and mode characteristics of heating platens with different type of heating. One the one hand, this technique should adequately consider the impact of all variables. On the other-to be universal for all types of platens and heaters.

\section{MATERIALS AND METHODS}

The following methodology of optimization is proposed on Fig. 1. A computer experiments are conducted on a deterministic mathematical model of heating platen in accordance with design of experiments methods on the first stage. Building of the response surface (dependence between variables and optimality criterion) on the base of experimental data and validation of approximation are conducted on the second stage. 


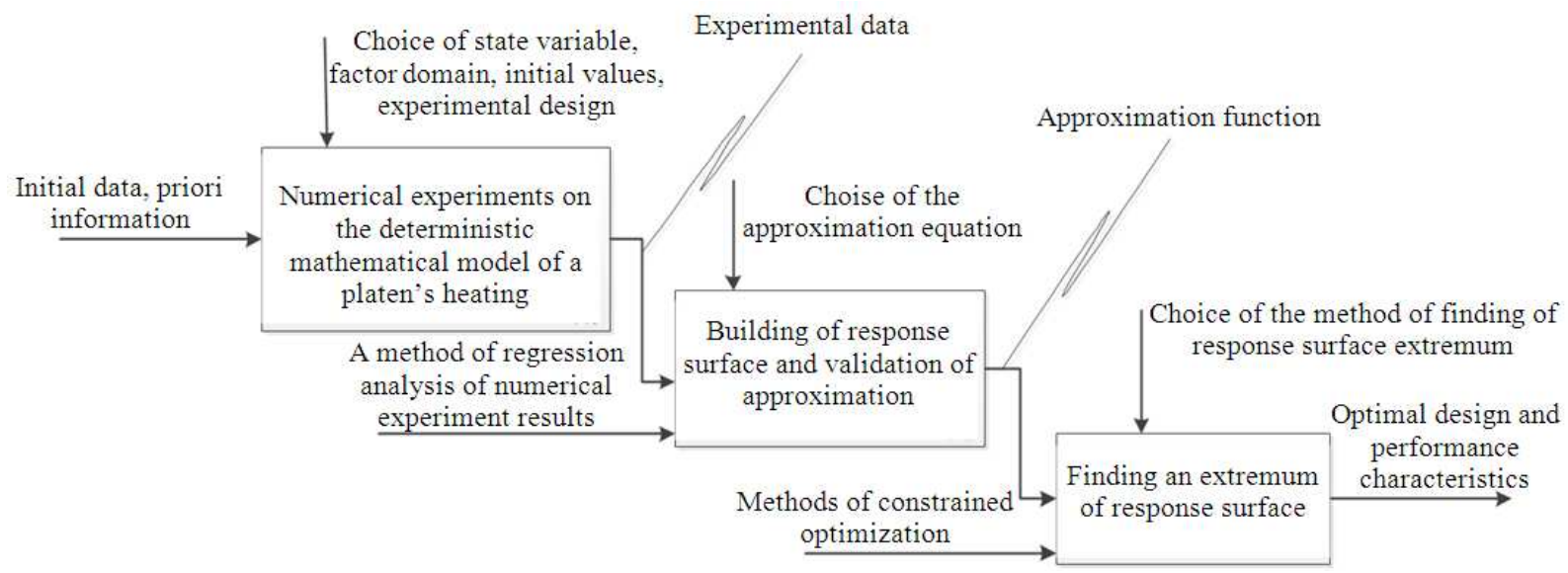

Fig. 1. Optimization scheme of structure and mode characteristics of heating system of press equipment

The values of variables corresponding to the response surface extremum will be the solution of optimization task. Their definition is carried on the third stage.

An induction heating platen with rectangular inductors implemented in manufacturing of rubber products in JSC "Zavod Tambovpolimermash" was used as an object of study (Fig. 2).

A heating platen with dimensions $\mathrm{l}=500, \mathrm{~s}=410, \mathrm{~h}$ $=70 \mathrm{~mm}$ has four inductors of rectangular shape with a sizes $172 \times 127 \mathrm{~mm}$ in slots of cross-section $25 \times 25 \mathrm{~mm}$. An average power of platen is $5 \mathrm{kWt}$.

The proposed optimization methodic on the stage of numerical experiments involves the following steps.

\subsection{Defining of a State Variable}

The purpose of chosen optimization methodology is uniform temperature field on the working surface of a platen. Therefore a temperature difference on the surface of platen is selected as a state variable, which is uniquely characterizes the efficiency of the object.

Note that it is possible to use other state variables, for example, variance of temperature or average temperature deviation. In our opinion, the use of the selected variable is preferred because of the ease calculations, which is important when conducting a series of numerical experiments.

Factor selection. To perform numerical experiments is necessary to identify the main factors influencing the magnitude of the temperature difference on the surface of platen. 5 factors are used for a platen with rectangular inductors (Fig. 2): Power $\left(\mathrm{x}_{1}=\mathrm{Q}\right)$, length $\left(x_{2}=1\right)$ and width $\left(x_{3}=s\right)$ of inductor, position of the center of inductor by the length and width of a platen $\left(\mathrm{x}_{4}=\mathrm{xc}, \mathrm{x}_{5}=\mathrm{yc}\right.$ respectively $)$.
Evaluation of factors domain. The choice of varying intervals is determined by following considerations. Intervals of varying of inductor's geometry should provide minimal distance between inductors as well as between inductor and edge of a platen equal to a width of a slot (25 $\mathrm{mm}$ ). The value of interval estimation of total power of a platen should be considered in a way to guarantee platen heating to the working temperature within the specified time. Note that factors domain finally formed in a preliminary experiments conducted according to the methodic described in (Karpushkin et al., 2011).

\subsubsection{Choice of Zero Levels}

The center of experimental design is combined with a center of factors domain in all cases. That approach is universal for all heating platens.

\subsubsection{Choice of Experimental Design}

It is a selection of a rule that will determine a set of values of all the factors of the object. Note that design order must be not less than the order of approximation equation (Myers and Montgomery, 2002).

\subsubsection{Building of a Response Surface}

It is a choice of approximation function and calculation of its coefficients as well as validation of approximation.

Approximation relates input parameters (factors) and state variable. As a rule, a functional dependence established in a polynomial form that in a case of 5 factors and experimental design of a second order is depicted as follows:

$$
f\left(x_{1}, x_{2}, x_{3}, x_{4}, x_{5}\right)=b_{0}+\sum_{i=1}^{5} b_{i} x_{i}+\sum_{i=1}^{5} \sum_{j=i}^{5} b_{i j} x_{i} x_{j}
$$




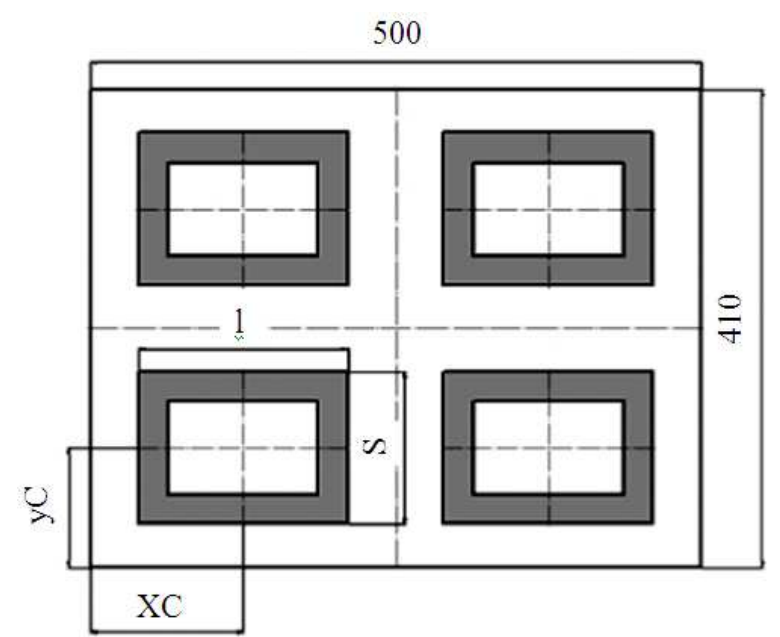

Fig. 2. The design of the heating plate with rectangular inductors

In this way, the task of approximation is to determine a polynomial coefficients $b$. The least-squares method is used for approximation (Lawson and Hanson, 1995).

\subsubsection{Search of Response Surface Extremum}

The solution of optimization task is values of factors corresponding to the minimum of response surface.

The choice approximation function type is topical because it determine accuracy of restoration of unknown functional dependence and optimization task solution in general. However there are no standard recommendations and conclusions which can be a strict theoretical basis for efficient realization. According to the experience, there is a strategy of consequent complication of dependencies during the selection of approximation function (Montgomery and Runger, 2003).

Glebov (2013) the comparison analysis of results obtained with implementation of linear, square and cubic approximations with two-stage Full Factor Design (FFD) of first order, three-stage FFD and fourstage FFD (third order) was conducted. Analysis has shown that it is expedient to use a second order polynomial since increasing of order is not leading to significant changing of results but calculation time has raised more than 3 times.

\section{RESULTS}

The choice of optimal experimental design task has no solution in a majority of cases. Therefore a search of optimal design provided according to the analysis of priori information about object and results of preliminary experiments (Ravindran et al., 2006). A three-level FFD, five-level orthogonal Central Composite Design (CCD) and three-level face-centered $\mathrm{CCD}$ were chosen for preliminary experiments. Also the rotatable CCD (Box and Hunter, 1957) characterized from orthogonal CCD by the length from axial points and non-compositional three-stage design (Box-Behnken design) which is a sample from FFD (Box and Behnken, 1960).

The results of FFD were basic since it has the highest number of experiments $3^{\mathrm{k}}$ (i.e., 243 calculations for a platen with rectangular inductors). For the rest of designs it is necessary to perform $2^{\mathrm{k}}+2 \mathrm{k}+1$ calculations (i.e., 43).

As seen in Fig. 3, axial points of orthogonal CCD are beyond factor domain that is unacceptable for chosen way of defining the varying of factors. Therefore an inscribed CCD (Fig. 3c) which is scaled orthogonal CCD of such way the axial points are belong to faces of a hypercube was used.

During rotatable design the number of experiments in the center of design is very important. It influences on the nature of distribution of information about response surface. According to the design of experiments theory for calculating experiment the reproducibility variance is zero, i.e., there are no differences in results of the same calculations. Nonetheless, the increasing of number of experiments in each point of a factor space is enhancing their "weight" in approximation: The link between a point and response surface is strengthen. The experiment in the center of 5 -factor rotatable design repeated 10 times (Box and Hunter, 1957).

Length from axial points in face-centered CCD is chosen equal to 1 (Fig. 3d). As a result, each factor varies by only three levels that is a drawback of that design.

Data for comparison analysis of applied experimental designs of the second order by solution of 5-dimensionl optimization task is shown in Table $\mathbf{1 .}$

According to the data of Table $\mathbf{1}$ we can conclude that maximum error of prediction of optimality criterion was obtained by using face-centered CCD. Maximum accuracy of prediction was derived from Box-Behnken design. Minimum of temperature difference was obtained by using rotatable CCD. It should be noted that the use of rotatable CCD gave results significantly different (at the third state variable, Table 1) from other experimental designs. Therefore, we can recommend rotatable $\mathrm{CCD}$ and Box-Behnken design for using in methodic of optimization of design and performance parameters of press' heating system. 


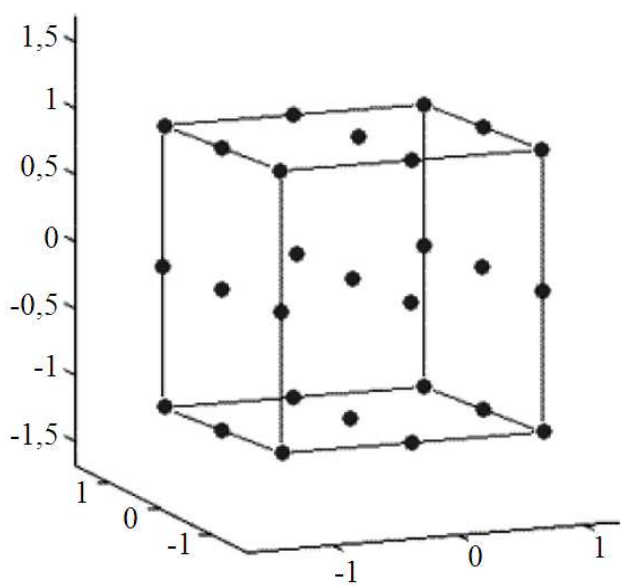

(a)

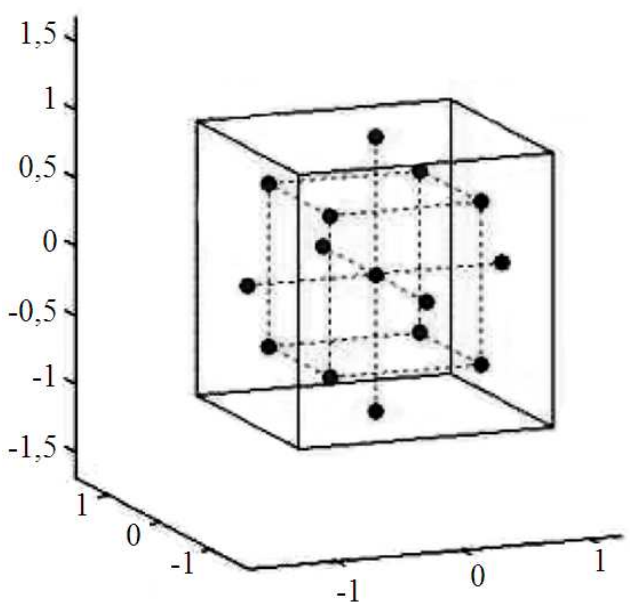

(c)

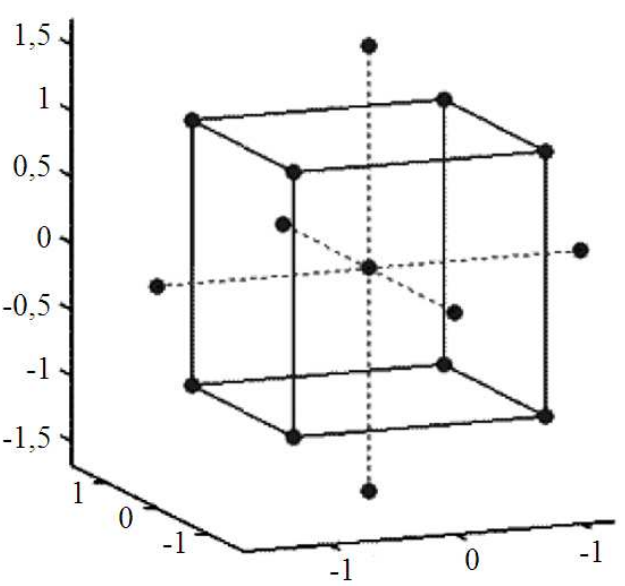

(b)

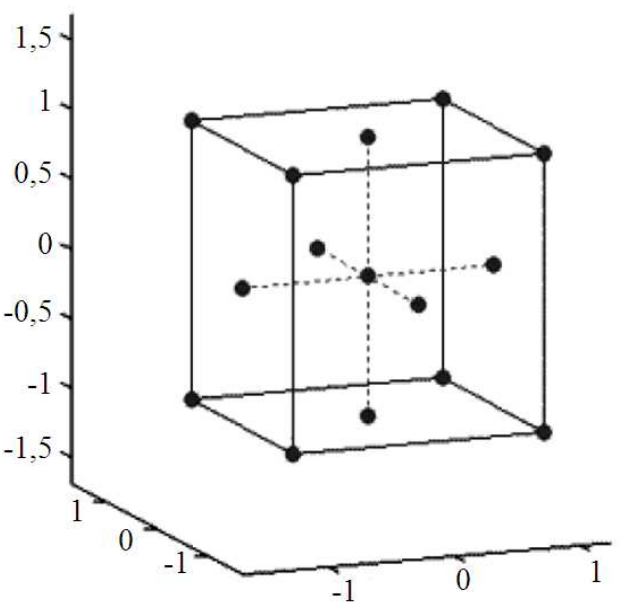

(d)

Fig. 3. Experimental designs for three factors: (a)-three-level FFD; (b)-circumscribed CCD; (c) -inscribed CCD; (d)-three-level facecentered CCD

Table 1. Comparison of experimental designs

\begin{tabular}{llllllllll}
\hline $\begin{array}{l}\text { Experimental } \\
\text { design }\end{array}$ & $\begin{array}{l}\text { No. } \\
\text { of stages }\end{array}$ & $\begin{array}{l}\text { No. of } \\
\text { calculations }\end{array}$ & $\begin{array}{l}\text { Optimal solution } \mathrm{X} \\
\mathrm{X}_{1}=\mathrm{Q}\end{array}$ & $\mathrm{X}_{2}=1$ & $\mathrm{X}_{3}=\mathrm{s}$ & $\mathrm{X}_{4}=\mathrm{xc}$ & $\mathrm{x}_{5}=\mathrm{yc}$ & $f(\mathrm{X})$ & $\begin{array}{l}\text { Verification } \\
\text { calculation } y(\mathrm{X})\end{array}$ \\
\hline FFD & 3 & 243 & 1100 & 213 & 170 & 128 & 100 & 7,1 & 8,87 \\
Orthogonal CCD & 5 & 43 & 1194 & 215 & 159 & 128 & 100 & 6,1 & 8,75 \\
Rotatable CCD & 5 & 43 & 1176 & 215 & 143 & 128 & 100 & 8,2 & 7,63 \\
Face-centered CCD & 3 & 43 & 1100 & 215 & 165 & 128 & 100 & 4,1 & 8,59 \\
Box-Behnken design & 3 & 41 & 1101 & 213 & 160 & 128 & 100 & 7,9 & 7,90 \\
\hline
\end{tabular}

Validation of approximation is realized after the defining of approximation function coefficients. The regression analysis of the results of computational experiments on deterministic mathematical model (Maruthachalam and Palaniswamy, 2011) is used for that.

The task of finding a minimum of response surface refers to the class of function of several variables with constraints extremum search. Those constraints are factors domain. Grid method and direct backward method (Himmelblau, 1972) were implemented to solve that problem. Quadratic polynomial was used as approximation function. The same results with two-level face-centered CCD were obtained in two cases when defining the minimum of response surface for a platen 
with rectangular inductors. However, according to the calculations, the use of direct backward method is preferable because of less sensitivity for initial step and slightly shorter calculation time.

\section{DISCUSSION}

Numerical experiments on the influence of factors on the state variable were performed according to the methodic in (Karpushkin et al., 2011; Malygin et al. 2013). The finite element method was used for solving equations of mathematical model of platens' heating. Note that chosen methodology of computation let to avoid intricate and laborious electromagnetic analysis.

The intervals of varying of factors are shown in Table 2.

Two parametrical 3D solid-state models were built preliminary in Solid Works software. Geometrical model was a quarter of the whole platen because of the symmetry property. This fact reduced the calculation time of one numerical experiment.

All calculations were performed in Comsol Multi physics software with implementation of Heat Transfer Module. The purpose was to obtain maximum and minimum temperatures on the working surface of a platen. A time interval of $2000 \mathrm{~s}$ was chosen as a reference point. For industrial platens that time step approximately corresponds to the time heating from initial ambient temperature to the operating temperature $\left(200^{\circ} \mathrm{C}\right)$. It is obvious that by varying the power of inductors the temperature on the surface will change significantly. However, as shown by preliminary numerical calculations, this fact has a weak impact on the magnitude of temperature difference because it determined by changing both of the maximum and minimum surface temperatures.

The quadratic approximation validation graph for a platen with rectangular inductors is shown on Fig. 4.

Approximation validation showed that the approximating functions adequately describe the results of numerical experiments. Moreover, there is a high strength association between the state variable and factors. Maximum error between calculations and approximation data was $0,96^{\circ} \mathrm{C}$.

The optimal values of the factors are shown in Table 3. The difference of temperature on the surface before optimization was $15,7^{\circ} \mathrm{C}$, after optimization- $7,6^{\circ} \mathrm{C}$.

Table 2. Minimum and maximum values of factors

\begin{tabular}{lcc}
\hline Factor & Minimum value & Maximum value \\
\hline $\mathrm{X}_{1}=\mathrm{Q}$ & 1100 & 1400 \\
$\mathrm{X}_{2}=1$ & 160 & 215 \\
$\mathrm{X}_{3}=\mathrm{s}$ & 115 & 170 \\
$\mathrm{X}_{4}=\mathrm{xc}$ & 95 & 110 \\
$\mathrm{X}_{5}=\mathrm{yc}$ & 120 & 136 \\
\hline
\end{tabular}

Table 3. Optimal values of factors

\begin{tabular}{lll}
\hline Factor & Initial value & Optimal value \\
\hline $\mathrm{X}_{1}=\mathrm{Q}, \mathrm{Wt}$ & 1250 & 1176 \\
$\mathrm{X}_{2}=1, \mathrm{~mm}$ & 172 & 215 \\
$\mathrm{X}_{3}=\mathrm{s}, \mathrm{mm}$ & 127 & 143 \\
$\mathrm{X}_{4}=\mathrm{xc}, \mathrm{mm}$ & 123 & 128 \\
$\mathrm{X}_{5}=\mathrm{yc}, \mathrm{mm}$ & 101 & 100 \\
\hline
\end{tabular}

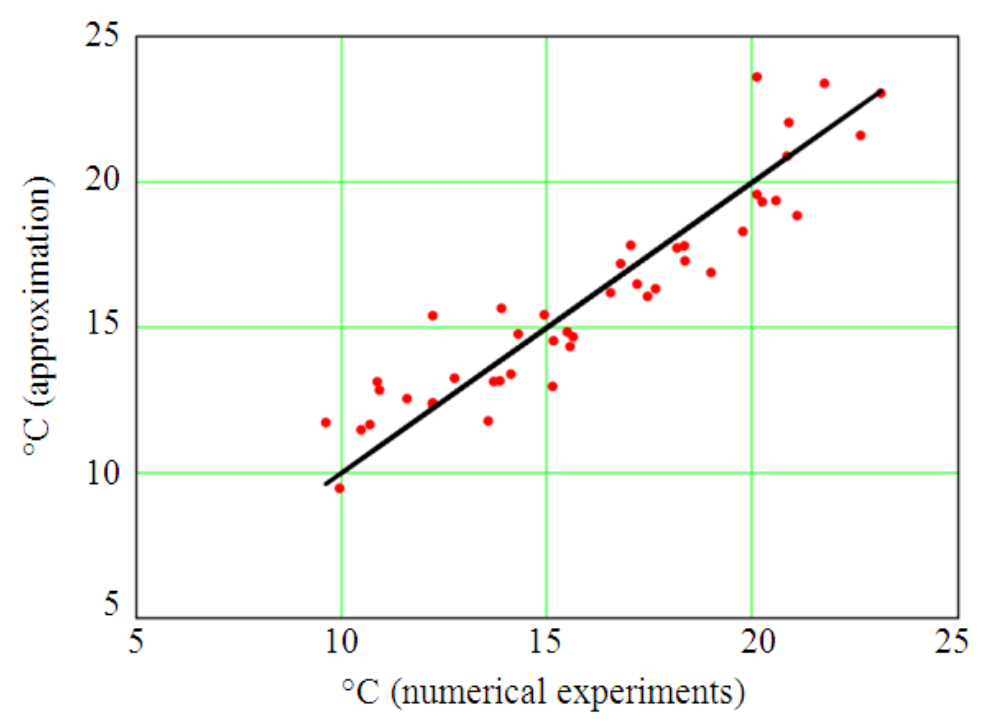

Fig. 4. Validation of quadratic approximation graph 
These conclusions support the achievement of the research objectives. In this way, the implementation of optimization for a platen with rectangular inductors makes possible to reduce the temperature difference in 2 times. The main prospects of described optimization methodic are implementation for the platens with steam and electric type of heating.

\section{CONCLUSION}

This research focuses on creating a method of design and performance characteristics' optimization for heating system of press equipment. Method is universal for all types of heating and different configuration of heaters and is based on the minimization of response surface extremum.

According to the performed comparison analysis of experimental designs the rotatable $\mathrm{CCD}$ and BoxBehnken design are preferable designs on the step of numerical experiments.

The procedure of optimization for industrial induction heating platen with four rectangular inductors has realized on the base of proposed methodic.

The future work of this research is to use more complicated mathematical models to increase the accuracy of determining temperature field on the surface of platens:

- For induction heating Maxwell equations should be considered

- For electric heating Joule equations should be taken into account

- For a steam heating criterion equations of condensation should be used in model

It should be noted that it will require an implementation of high-performance computing because of examined physical processes' complexity and large number of calculations.

\section{REFERENCES}

Abhilash, P.M., K. Kannan and B. Varkey, 2010. Simulation of curing of a slab of rubber. Materials Sci. Eng. B, 168: 237-241. DOI: 10.1016/j.mseb.2009.12.035

Avaev, A.A., Y.R. Osipov and V.V. Pavlov, 2010. Two-dimensional mathematical model of nonstationary heat conduction during thermal vulcanization of elastomeric coatings on a fabric backing. Chemical Petroleum Eng., 46: 14-16. DOI: $10.1007 / \mathrm{s} 10556-010-9282-0$
Box, G.E.P. and D.W. Behnken, 1960. Some new three level designs for the study of quantitative variables. Technometrics, 2: 455-475. DOI: 10.1080/00401706.1960.10489912

Box, G.E.P. and J.S. Hunter, 1957. MultiFactor experimental designs for exploring response surfaces. Annals Math. Stat., 28: 195-241. DOI: 10.1214/aoms/1177707047

Dmitriev, O.S., V.N. Kirillov, S.V. Mischenko and A.O. Dmitriev, 2010. Computer-measuring system for research into properties of glutinous prepregs and calculation of curing cycles of the polymer composite materials on their base. Polymer Sci. D, 3: 20-25. DOI: 10.1134/S199542121001003X

Dmitrievskii, V.A., V.A. Prakht, F.N. Sarapulov and V.A. Klimarev, 2012. A finite element model of electric machine with flux switching-over for studying the dynamic operation modes. Russ. Electr. Eng., 83: 126-131. DOI: 10.3103/S1068371212030042

Galunin, S., Y. Blinov, A. Nikanorov, H. Schülbe and G. Nauvertat et al., 2001. Application of genetic algorithms for optimization of transverse flux induction heating systems. Proceedings of the International Seminar on Heating by Internal Sources, (HIS' 01), Padua, pp: 625-630.

Glebov, A.O., 2013. Method of optimization of design and performance characteristics of heating plate of vulcanizing press. Trans. Tambov State Tech. Univ., 19: 137-151.

Himmelblau, D.M., 1972. Applied Nonlinear Programming. 1st Edn., McGraw-Hill, New York, pp: 498.

Ilona, I., L. Ilonka, T. Hristophor and S. Rumena, 2008. Industrial heating system creating given temperature distribution. Serbian J. Electrical Eng., 5: 57-66.

Karpov, S.V. and S.V. Karpushkin, 2012. Determination of efficiency of press molds for industrial rubber product manufacture and system for their heating in vulcanizing press. Chemical Petroleum Eng., 48: 153-162. DOI: 10.1007/s10556-012-9591-6

Karpushkin, S.V., S.V. Karpov and A.O. Glebov, 2011. Modeling of induction heating devices in example of induction heating platens of vulcanization presses. Trans. Tambov State Technical Univ., 17: 110-120. 
Lawson, C.L. and R.J. Hanson, 1995. Solving Least Squares Problems. 1st Edn., Society for Industrial and Applied Mathematics, Philadelphia, ISBN-10: 0898713560 , pp: 337.

Malygin, E.N., S.V. Karpushkin and S.V. Karpov, 2013. Modeling and calculating processes of induction heating for press equipment during manufacture of rubber products. Sci. Educ., 3: 85104. DOI: $10.7463 / 0313.0541632$

Maruthachalam, S. and N. Palaniswamy, 2011. Determination of flux linkage characteristics and inductance of a submersible switched reluctance motor using software tools. J. Comput. Sci., 7: 179-187. DOI : 10.3844/jcssp.2011.179.187

Montgomery, D.C. and G.C. Runger, 2003. Applied Statistics and Probability for Engineers. 3rd Edn.. John Wiley and Sons, New York.
Myers, R. and D. Montgomery, 2002. Response Surface Methodology: Process and Product Optimization Using Designed Experiments. 2nd Edn., Wiley-Interscience, Wiley Series in Probability and Statistics.

Mihaela, N., V. Ecaterina, N. Ovidiu and G. Mircea, 2009. Aspects regarding the optimization of the induction heating process using fmincon, minimax functions and simple genetic algorithm. J. Electrical Electron. Eng., 2: 64-69.

Ravindran, A., K.M. Ragsdell and G.V. Reklaitis, 2006. Engineering Optimization: Methods and Applications. 2nd Edn., Wiley, Hoboken, N.J., ISBN-10: 0471558141, pp: 667.

Taher, S.A., R. Hematti and M. Nemati, 2008. Comparison of different control strategies in GAbased optimized UPFC controller in electric power systems. Am. J. Eng. Applied Sci., 1: 45-52. DOI: 10.3844/ajeassp.2008.45.52 